\title{
Optimization of Mixture Proportions of High Strength High Performance Concrete Incorporating Rice Husk Ash by Using Response Surface Methodology
}

\author{
Syamsul Bahri ${ }^{1}$, H.B Mahmud ${ }^{2}$ and Payam Shafigh ${ }^{3,4}$ \\ \{ syamsul_b62@yahoo.com \} \\ ${ }^{1}$ Dept. of Civil Engineering, Politeknik Negeri Lhokseumawe, Lhokseumawe, Indonesia \\ ${ }^{2}$ Dept. of Civil Engineering, University of Malaya, Kuala Lumpur, Malaysia \\ ${ }^{3}$ Dept. of Building Surveying, University of Malaya, Kuala Lumpur, Malaysia \\ ${ }^{4}$ Center for Building, Construction \& Tropical Architecture (BuCTA), Faculty of Built Environment, \\ University of Malaya, 50603 Kuala Lumpur, Malaysia
}

\begin{abstract}
Five key variables of high-strength high performance concrete (HSHPC) were considered in the models developed such as water-to-binder ratios (w/b), binder contents, percentages of partial cement replacement with rice husk ash (RHA), ratios of fine aggregate to total aggregate (fa/ta), and percentages of superplasticizer dosage. Box Behnken Design (BBD) experiment and response surface methodology (RSM) were applied to determine the models that can optimize mix proportion consisting of the five variables with three levels leading to optimal slump value, compressive strength at age of 1 and 28-days. The quadratic model is statistically acceptable compared other models. The prediction of optimum values and the clarification of the interactions between the specified range factors were done by using the quadratic model and analysis of variance (ANOVA). The models were able to accurately predict the response of slump and compressive strength of HSHPC less than 5\% error. The results proved that the models show that ratio $\mathrm{w} / \mathrm{b}$, binder contents, percentages of partial cement replacement with RHA and percentages of superplasticizer dosage have a significant effect on the slump and compressive strength of concrete. It shows that the proposed response models provide useful information regarding the mixture optimization for securing target strength and cost-effective of HSHPC.
\end{abstract}

Keywords: Rice husk ash; optimization; high strength performance concrete; response surface methodology, Box-Behnken Design.

\section{INTRODUCTION}

Many researchers had explored the idea of improving chemical and physical properties of RHA to be utilized in concrete. Previous studies on the RHA as supplementary cementious material in the concrete are mainly in the fineness of RHA [1], [2] the carbon content of RHA [3] the mechanical and durability properties in strength of normal concrete (NSC) [4] and high performance concrete [5]. 
Now, the research trend focuses on high strength and high performance concrete (HSHPC) as the demand is increasing on compressive strength of HPC above 80 MPa lately. The concrete industries need HSHPC in order to construct high rise buildings, to increase the space of occupation, to reduce dead load through reducing the size of element and to improve durability as well. The lower columns of high rise building of .Petronas Towers had used concrete with compressive strength of $80 \mathrm{MPa}$ The common strategy to produce HSHPC is by applying low w/b, Supplementary cementicious material (SCM) and highly percentages dosage of superplasticizer [6], [7]. Applying a water/binder ratio of less than 0.3 and SCM as partly cement subtitution greatly improves the microstructure and the qualities of the transition zone of concrete [8]. However, the guide for mix proportion of concrete for compressive strength above $60 \mathrm{MPa}$ and involving SCM is beyond any available codes and mostly concrete producers providing the concrete by trial and error procedures which are time consuming and increase the concrete cost.

In the past, a few studies have been conducted to establish the mix proportions and investigate the performance of concrete containing RHA, especially in high performance concrete, 80 up to $110 \mathrm{MPa}$. The partial cement replacement with RHA in concrete increase the level hydration of cement, reduce the pore structure and the $\mathrm{CaOH}$ content in [9]-[11]. Partial replacement cement with RHA can be utilized up to $30 \%$ without affecting the strength and permeability properties of normal concrete (Bui et al., 2012). Ganeshan [1], [12] investigated the effects of normal concrete incorporating 20\% RHA as partial cement subtitution at three different particle sizes and obtained that the strength of concrete was improved at later age. In spite of a lot of information available in the existing literature on incorporating RHA as SCM, the applied procedures that for optimizing mix proportion of concrete having the compressive strength up to $100 \mathrm{MPa}$ are quite limited. There are some researchers working on developing statistical models for optimizing concrete mixtures to find the required engineering properties. [13] presented a model to predict the compressive strength of silica fume concrete up to $85 \mathrm{MPa}$ at 28-days with water-to-cementitious material $(\mathrm{w} / \mathrm{cm})$ ratios varying from 0.30 to 0.42 and percentages replacement of silica fume from $5 \%$ to $30 \%$, which developed by using statistical methods. Ghesal and Khayat [14] utilized factorial design and RSM to optimize a four-component concrete containing limestone filler subject to eight performance criteria. Li et al. [15] utilized Boh-Behnken experiments and response surface method to model alkali slag concrete of normal concrete under freeze-thaw cycles. Islam et al. [9] conducted statistical method to predict the strength of HPC incorporating RHA for compressive strength in the varying of 40-90 $\mathrm{MPa}$. However, they did not mention the particle size of RHA and mixing method used as both of them are critical parts of producing concrete incorporating RHA [7]. Furthermore, the model did not present the early strength age which is important information for concrete industries for enables early stripping formwork and its economic reasons.

In the present study, Box-Behnken Design experimental and RSM were used to model and optimize the ingredient of mix proportion leading to maximum slump value, 1 and 28-day compressive strength. Five key variables having significant effects on mix characteristics of HSHPC were designated to derive mathematical models for estimating relevant responses. Those models are valid for mixes made with w/b ratios of 0.22 to 0.28 , binder content in the varying of 500 to $600 \mathrm{~kg} / \mathrm{m}^{3}$, partial cement replacement with RHA up to 20\%, a fine to total aggregate ratio $(\mathrm{fa} / \mathrm{ta})$ of $0.35-0.45$, percentages of the $\mathrm{Sp}$ dosage of solid content in the varying of $0.4-1.3 \%$. 46 mix proportions were casted and veryfied for developing suitable models to predict responses on slump value, compressive strength of concrete at age of 1 and 28-days. An additional mixture was prepared for verifying the optimum mix proportion 
predicted by models for specific requirement on HSHPC. Those models could be useful to reduce the tests and the number of trial mixes of HSHPC. It will be beneficial in term of cost and time consuming for concrete industries and engineers aimed to utilize RHA as partially cement subtitusion in HSHPC.

\section{MATERIALS AND METHODS}

\subsection{Raw materials and preparation}

Table 1 shows the chemical and physical properties of cement and RHA. The ingredient of HSHPC is alike to regular concrete except incorporating SCM and high dosage of superplasticizer. Materials used were cement, RHA, aggregates, water and superplasticizer. Ordinary Portland cement (OPC) used Type I class 42.5 from a local supplier and its specific surface area and specific gravity are $3280 \mathrm{~m}^{2} / \mathrm{kg}$ and 3.15 , respectively. RHA was produced by uncontrolled burning in ferrocement furnace, but the temperature of burning did not exceed $700{ }^{0} \mathrm{C}$ so that it is expected in amorphous form. RHA was ground for 16000 cycles by LA machine and its average particle size was $13 \mu \mathrm{m}$. Its surface area and specific gravity was $23455 \mathrm{~m}^{2} / \mathrm{kg}$ and 2.06, respectively. Major chemical composition of RHA consists of $\mathrm{SiO}_{2}$, above $85 \%$, and LOI content of $4.1 \%$ which complies with ASTM C618 requirement. The specific gravities of crushed granite aggregate and mining sand and are 2.7 and 2.6, respectively. Figure 1 shows the particle size distribution of solid igradients. It shows that the particle size of RHA is finer than that of OPC which is expected it can be function as pozzolanic material and fillers to improve microstructure of concrete [16].

Aggregates were washed to minimize the clay in mining sand and dust in crushed granite. The mixtures were mixed with tap water which was clean and free from any visible impurities. The fresh properties of concrete were recorded through a slump test. Then the mixture was moulded and placed on a tremor table for 60-90 s. The specimen was covered by plastic to protect from water evaporation. After 24 hours, the moulds were dismantled and the specimen was cured in water tank until test age.

Table 1. Chemical composition of Cement and RHA

\begin{tabular}{ccc}
\hline Chemical components $(\%)$ & OPC & RHA \\
\hline Magnesium oxide $(\mathrm{MgO})$ & 2.06 & 0.81 \\
Aluminum oxide $\left(\mathrm{Al}_{2} \mathrm{O}_{3}\right)$ & 5.60 & 0.25 \\
Silicon dioxide $\left(\mathrm{SiO}_{2}\right)$ & 21.28 & 85.76 \\
Sulfate $\left(\mathrm{SO}_{3}\right)$ & 2.14 & 0.31 \\
Calcium oxide $(\mathrm{CaO})$ & 64.64 & 0.74 \\
Iron oxide $\left(\mathrm{Fe}_{2} \mathrm{O}_{3}\right)$ & 3.38 & 1.15 \\
Loss of Ignition $(\mathrm{LoI})$ & 0.60 & 4.05 \\
\hline
\end{tabular}




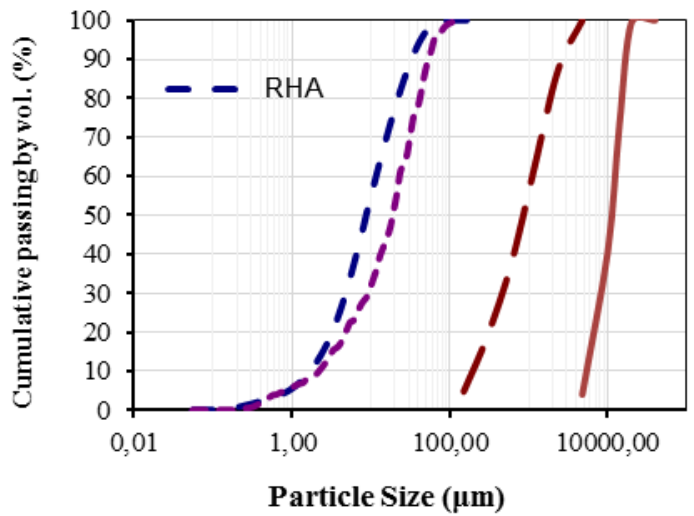

Fig. 1 Particle distributions of solid ingredient of HSHPC

In this study, the packing density of aggregate considered through the ratio of fine aggregate to total aggregate (fa/ta). Figure 2 shows that the optimum packing density of aggregates is close to the ratio fa/ta of 0.45. Previous models developed by Islam et al. [9], the amount of fine and coarse aggregate were incorporated without considering the packing density of the aggregates. The extreme packing density of aggregates produced the lowest void that lead to concrete having lowest cement consumption, porosity, shrinkage, highest performance and the lowest price [17]. However, Damone [18] suggested to apply the ratio fa/ta slightly lower than the optimum packing density to avoid harsh mixes. Figure 2 shows that the optimum packing density of aggregates is 0.69 at the ratio fa/ta of 0.45 . In this study, the ratios fa/ta adopted were in the varying of $0.35-0.45$.

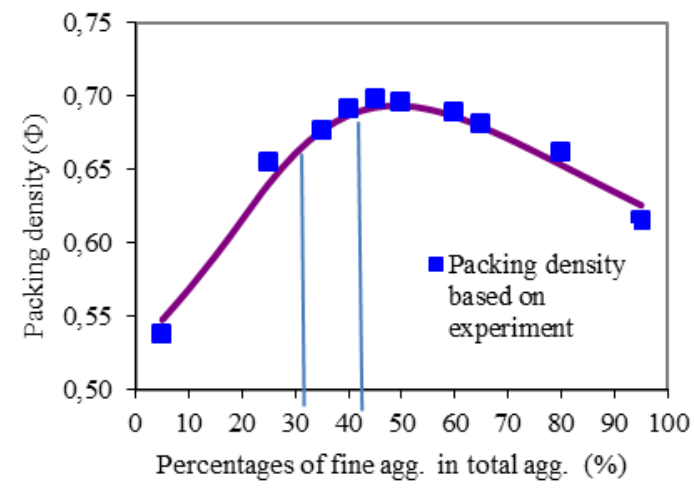

Fig. 2 Packing densities of various ratios of $\mathrm{fa} / \mathrm{ta}$

\subsection{Methods}

The fresh properties of concrete were tested through slump test based on BS 1881-102. The strength of concrete was tested trough universal test machine capacity of $2000 \mathrm{kN}$ based on the BS 1881-116. The compressive strength of concrete was conducted at 1 and 28 days. A total of 46 HSHPC mixtures were tested in this study and their responses were exploited to 
obtain models for predicting the responses designed and optimizing the mixture proportions of HSHPC using a response surface methodology.

\subsection{Experimental design and data analysis}

The Box-Behnken experimental design was preferred for finding out the relationship between variables (w/b, binder, RHA, ratio fa/ta and Sp dosage) for three different levels and the response functions (slump value, 1 and 28 days compressive strength). The models proposed by the Design Expert software (Statease Inc., Minneapolis, MN55103) are chosen through some criteria which satisfy to represent the effects of the mixture components and their interaction on the responses of slump $\left(\mathrm{Y}_{1}\right)$, 1-day compressive strength $\left(\mathrm{Y}_{2}\right)$ and 28-days compressive strength $\left(\mathrm{Y}_{3}\right)$. Table 2 shows independent variables and each their levels for the design used in this study. Based on five variables and three levels, the total of experiments run in BBD can be calculated as $\mathrm{N}=2 \mathrm{k}(\mathrm{k}-1)+\mathrm{Co}$, where $\mathrm{k}$ is the total of variables and Co is the total of central points applied. The total of central point adopted is 6 runs and then the totals of the run are 46 runs.

Table 2. The level of variables chosen for the Box-Behnken design

\begin{tabular}{lcccc}
\hline & & \multicolumn{3}{c}{ Coded variable level } \\
\cline { 3 - 5 } \multicolumn{1}{c}{ Variables } & Symbol & Low & Centre & High \\
\cline { 3 - 5 } & & -1 & 0 & +1 \\
\hline W/b & $\mathrm{A}$ & 0.22 & 0.25 & 0.28 \\
Binder & $\mathrm{B}$ & 500 & 550 & 600 \\
RHA & $\mathrm{C}$ & 0 & 10 & 20 \\
fa/ta & $\mathrm{D}$ & 0.35 & 0.40 & 0.45 \\
Dosage of Sp & $\mathrm{E}$ & 0.40 & 0.85 & 1.30
\end{tabular}

The mixture proportions were calculated based on the absolute volume method. From the list of run of the Box-Behnken design, the actual mix proportions of concrete were calculated by the Eq. 1-5. After determining the mixture proportions, all materials are prepared such as the mass of cement, rice husk ash, fine aggregate, coarse aggregate and the amount of Sp. All mixtures were mixed by a 1501 pan mixer. The mixing method adopted was a two-step mixing, which involves mixing slurry of cementitious materials, water and fine aggregate, then adding coarse aggregate to form concrete.

$$
\begin{aligned}
& \mathrm{M}_{\mathrm{C}}=\mathrm{M}_{\text {Binder }}-\% \mathrm{RHA} * \mathrm{M}_{\text {Binder }} \\
& V_{C r}=V_{w}+V_{C}+V_{R H A}+V_{C A}+V_{F A}+V_{S P}+V_{A} V_{c \mathrm{r}}=1 \mathrm{~m}^{3}=10001 \\
& V_{m}=1000-\left(V_{w}+V_{c}+V_{R H A}+V_{S p}+V_{a}\right) \\
& M_{F A}=\frac{V_{m}}{\left(\frac{1}{\rho_{F A}}+\frac{(1-X)}{\left(X * \rho_{C A}\right)}\right)} \\
& M_{C A}=\left(V_{m}-\frac{M_{F A}}{\rho_{F A}}\right) \rho_{C A}
\end{aligned}
$$

Where, $\mathrm{X}$ is the ratio of fine to total aggregate (fa/ta), $V_{C r}$ is the volume of concrete, $V_{w}$ is the volume of water, $V_{C}$ is the volume of cement, $V_{R H A}$ is volume of RHA, $V_{C A}$ is the volume of coarse aggregate, $V_{F A}$ is the volume of fine aggregate, $V_{S p}$ is the dosage of $\mathrm{Sp}, V_{A}$ is the volume 
of air $(1.5 \%), V_{m}$ is the volume of mortar, $M_{F A}$ is the mass of fine aggregate, $M_{F A}$ is the mass of fine aggregate, $M_{C A}$ is the mass of coarse aggregate, $\rho_{F A}$ is the specific gravity of fine aggregate, $\rho_{C A}$ is the specific gravity of coarse aggregate.

The relationship between the variables and the responses can be estimated by mathematical model of the second order polynomial, Eq (6):

$$
Y_{i}=a_{0}+\sum_{i=1}^{n} a_{i} x_{i} \sum_{i=1}^{n} a_{i i} x_{i}^{2}+\sum_{i=1}^{n} \sum_{i=1}^{n} a_{i j} x_{i} x_{j}+e
$$

Where $Y_{i}$ is the predicted response; $a_{0}$ is model constant; $x_{i}$ is independent variables; $a_{i}$ are linear coefficients; $a_{i j}$ are cross product coefficients and $a_{i i}$ are the quadratic coefficients This section must be in one column.I

\section{RESULTS AND DISCUSSIONS}

\subsection{Developed Models}

Table 3 shows the summary of various models analyzed by Design Expert software, which are quadratic and cubic. The criteria used to govern the appropriate models adopted based on statistic parameters such as coefficient of determination $\left(\mathrm{R}^{2}\right)$, adjusted $\mathrm{R}^{2}$, adequate precision, the prediction error sum of squares (PRESS), p-value for lack of fit test, and aliased data. Predicted $\mathrm{R}^{2}$ is a measurement of how good the model expects a response value (Lachiver et al., 2006). Furthermore, the models also checked for adequate precision which dealings the signal to noise ratio. They also compared the range of the predicted values at the design points to the average prediction error. The value was found greater than 4 which is desirable and indicates the reliability of the experiment data. Only quadratic and cube model show the p-value for lack of fit test greater than 0.05 which implies the models are not significant relative to the pure error and it means that the models are good. Eventually, the Rsquare of the quadratic model shows lower than that of the cubic model, but other side the PRESS value of the quadratic model show lower than that of the cubic model. In addition, Table 4 shows that the cubic models are aliased due to the insufficient unique design points to estimate all the coefficients for the chosen model. So that, it can be decided that quadratic model is the most proper model for predicted the mix proportion applied in HSHPC. The coefficient of determination $\left(\mathrm{R}^{2}\right)$ of the models for the response of slump, 1 and 28-days compressive strength was $0.9943,0.9810$ and 0.9858 , respectively, which indicated a good fit between predicted values and the experimental data points.

Table 3. Summary proposed models by the Design Expert software

\begin{tabular}{|c|r|r|r|r|c|}
\hline \multirow{2}{*}{ Responses } & Models & R-Squared & $\begin{array}{l}\text { Adeq. } \\
\text { Precis. }\end{array}$ & PRESS & $\begin{array}{c}\text { p-value } \\
\text { for Lack of fit } \\
\text { test }\end{array}$ \\
\hline \multirow{2}{*}{ Y1 } & Q.dratic & 0.9943 & 53.775 & 1965.58 & 0.138 \\
\cline { 2 - 6 } & Cubic & 0.9989 & - & 3544.11 & 0.459 \\
\hline \multirow{2}{*}{ Y2 } & Q.dratic & 0.9810 & 31.86 & 499.07 & 0.112 \\
\cline { 2 - 6 } & Cubic & 0.9913 & & 3090.53 & 0.073 \\
\hline Y3 & Q.dratic & 0.9858 & 36.45 & 549.12 & 0.087 \\
\hline
\end{tabular}




\begin{tabular}{|l|l|l|l|l|l|}
\hline & Cubic & 0.9964 & - & 1690.99 & 0.150 \\
\hline
\end{tabular}

\subsection{Statistical Analysis}

Best-fits of the models were developed for HSHPC properties e.g., slump, 1 and 28 dayscompressive strength. To find the relation between the input variables and the responses on quadratic models, Analysis of variance (ANOVA) was utilized. The confidence interval (CI) adopted is $95 \%$, which means that if the probability greater than 't-statistic' is less than 0.05 $(5 \%)$, the model or variable has significant influence on the responses. Table 4 indicates that the results of ANOVA analysis for models appears that the probabilities of regression models greater than "F statistic" (Fisher statistic) are less than 0.0001. It means that the models are highly statistically significant with confidence interval more than $99.99 \%$. In addition, the lowest $\mathrm{R}^{2}$ values are $96.74 \%$, which is an signal of reasonably good fitness. The model also were checked its relation to pure error through the p-value of models for lack of fit test, which are greater than 0.05 and implies the lack of fit for all models are not significant relative to the pure error and it means that the models are good.

Table 4. Summary statistics of slump and compressive strength strength of reduced quadratic model

\begin{tabular}{|c|c|c|c|}
\hline $\begin{array}{l}\text { Regression } \\
\text { coefficients }\end{array}$ & Slump & $\begin{array}{c}\text { Comp. } \\
\text { strength of } \\
\text { concrete at } 1 \\
\text { day } \\
\end{array}$ & $\begin{array}{c}\text { Comp. } \\
\text { strength of } \\
\text { concrete at } \\
28 \text { days } \\
\end{array}$ \\
\hline$P$-value & $<0.0001^{* * * *}$ & $<0.0001 * * *$ & $<0.0001^{* * *}$ \\
\hline $\mathrm{R}^{2}$ & 0.9937 & 0.9674 & 0.9838 \\
\hline F-v L of fit & 2.27 & 2.87 & 3.15 \\
\hline$P$-v L of fit & $0.1837 * * * *$ & $0.1211 * * * *$ & $0.1022 * * * *$ \\
\hline
\end{tabular}

All the five variables such as a water binder ratio (A), binder content (B), partial percentages of cement replacement with RHA (C), ratio of fine aggregate to total aggregate (D) and percentages dosage of superplasticizer (E) were tested individually for 't statistic'. The probability greater than 't statistic' for intercept, all variables, and their interaction are indicated "*” in Table 5. The probabilities greater than 't statistic' are found to be less than 0.001 (confidence level more than 99.99\%) for all variables except binder content (B) in the model of 1-day compressive strength and ratio of fine aggregate to total aggregate (D) in all models. All variables except the ratio of fine aggregate to total aggregate (D) are statistically significant and have direct influence on slump, 1 and 28 days-compressive strength at. It was possible due to the ratios fa/ta between the lower and the higher value are not significantly change the packing density value as the ratios ta/fa of 0.35 and 0.45 are 0.676 and 0.693 , respectively. Also, all input variables have positive impacts on slump value except binder content (B) and partial cement replacement with RHA (C). Increasing binder content and cement replacement with RHA reduce the slump value while maintaining other variables constant was also reported [19]. 
Table 5. Model terms and their significance of slump and the 1 and 28-day strength model

\begin{tabular}{|c|c|c|c|}
\hline \multirow[b]{2}{*}{$\begin{array}{l}\text { Regression } \\
\text { coefficients }\end{array}$} & \multicolumn{3}{|c|}{ Coefficients for reduced model } \\
\hline & Slump & $\begin{array}{l}\text { 1-day comp. } \\
\text { strength of } \\
\text { concrete }\end{array}$ & $\begin{array}{l}\text { 28-day comp. } \\
\text { strength of } \\
\text { concrete }\end{array}$ \\
\hline$a_{0}$ & +1076.15 & -2005.59 & -1484.31 \\
\hline$a_{1}$ & -3415.51 & +3979.23 & +1492.29 \\
\hline$a_{2}$ & -2.84 & +4.37 & +4.089 \\
\hline$a_{3}$ & -1.65 & +1.98 & +1.28 \\
\hline$a_{4}$ & +1390.07 & +1399.64 & +991.21 \\
\hline$a_{5}$ & +150.79 & +84.15 & +85.94 \\
\hline$a_{12}$ & +7.83 & - & +3.35 \\
\hline$a_{13}$ & +22.50 & +21.17 & +29.50 \\
\hline$a_{14}$ & - & - & - \\
\hline$a_{15}$ & -685.19 & - & -331.48 \\
\hline$a_{23}$ & -0.017 & -0.016 & -0.01 \\
\hline$a_{24}$ & - & - & - \\
\hline$a_{25}$ & +0.72 & - & +0.23 \\
\hline$a_{34}$ & - & - & - \\
\hline$a_{35}$ & +3.50 & - & - \\
\hline$a_{45}$ & - & - & - \\
\hline$a_{1}^{2}$ & - & -8345.12 & -6981.48 \\
\hline$a_{2}^{\frac{1}{2}}$ & - & $-3.74 \mathrm{E}-003$ & $-4.38 \mathrm{E}-003$ \\
\hline$a_{3}^{2}$ & - & - & -0.15 \\
\hline$a_{4}^{2}$ & - & -+1744.242 & -1226.67 \\
\hline$a_{4}$ & +1723.53 & - & - \\
\hline$a_{5}^{2}$ & +164.49 & -40.63 & -53.70 \\
\hline
\end{tabular}

Notes:

$\mathrm{a}_{\mathrm{i}}$ : estimated regression for the main linear effects;

$\mathrm{a}_{\mathrm{ij}}$; the estimated regression coefficients for the quadratic effects.

Some variables are interacting with each other. Some of them have a positive influence and others have a negative influence on the response. Interaction $\mathrm{w} / \mathrm{b}$ and the binder and the RHA are significant positive influences on the slump and strength of concrete. However, interaction between w/b and the dosage of $\mathrm{Sp}$ and between binder and RHA are significantly negative influences on the slump and strength. On the other side, interaction binder and the dosage of SP have a positive influence on the slump and later strength

After considering significant variables influenced on the models as shown in Table 6, the reduced models were proposed for slump, compressive strength at 1 and 28 days shown in Eq. 6-8. The real and expected values of slump and compressive strength at the age of 1 and 28 days are presented in Figs.3. Predicted values match with the experimental data points as indicating by $R^{2}$ closed to $1\left(R^{2}\right.$ value of 0.9945 for slump, $R^{2}$ value of 0.9748 for 1 -day compressive strength and $\mathrm{R}^{2}$ value of 0.9856 for 28 -day compressive strength). The fitted regression equation shows a good fit of the model.

The proposed model for Slump value is: 
$\mathrm{Y} 1=+1076.15-3415.51(\mathrm{~A})-2.84(\mathrm{~B})-1.65(\mathrm{C})+1390.07(\mathrm{D})+150.79 \mathrm{E})+7.83(\mathrm{~A})(\mathrm{B})+$ $22.50(\mathrm{~A})(\mathrm{C})-685.19(\mathrm{~A})(\mathrm{E})-0.017(\mathrm{~B})(\mathrm{C})+0.7(\mathrm{~B})(\mathrm{E})+3.50(\mathrm{C})(\mathrm{E})-1723.53(\mathrm{D})^{2}-$ $164.49(\mathrm{E})^{2}$

The proposed model for compressive strength of concrete at age of 1-day is:

$\mathrm{Y} 2=-2005.59+3979.23(\mathrm{~A})+4.37(\mathrm{~B})+1.98(\mathrm{C})+1399.64(\mathrm{D})+84.15(\mathrm{E})+21.17(\mathrm{~A})(\mathrm{C})-$

$0.02(B)(C)-8345.12(A)^{2}-0.0037(B)^{2}-1744.24(D)^{2}-40.63(E)^{2}$

The proposed model for compressive strength of concrete at age of 28-days is:

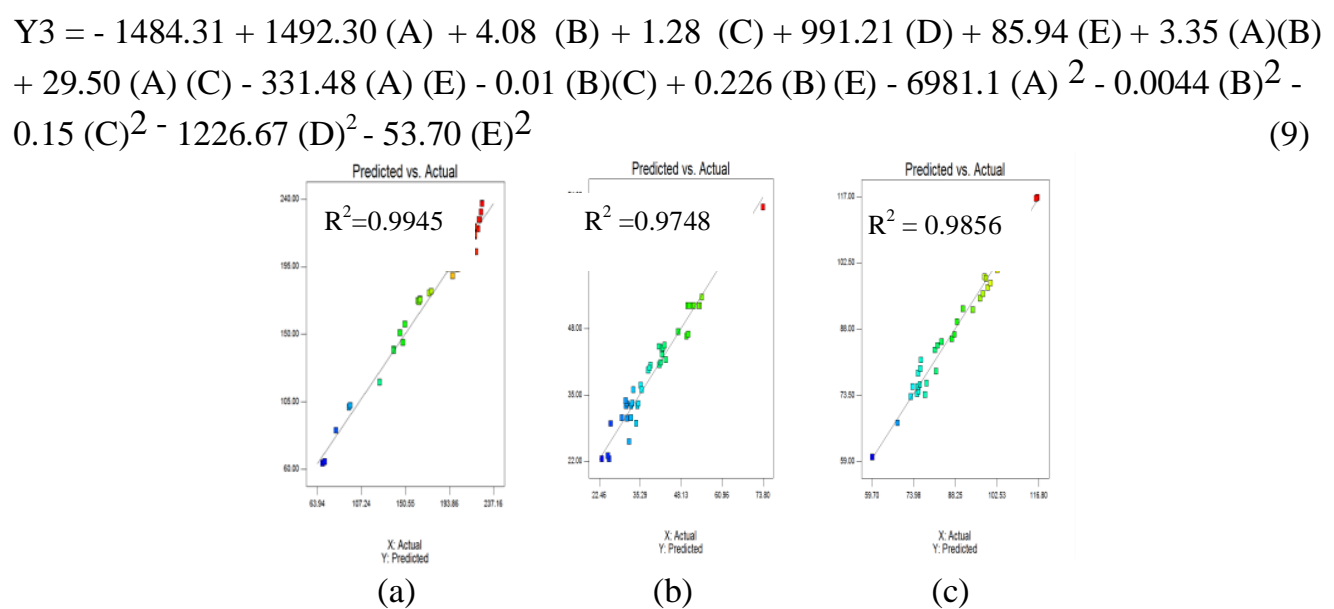

Fig. 3 Predicted and actual responses for (a) slump value (b) 1 day-compressive strength (c) 28 days-compressive strength

\subsection{Effects of W/b, Binder, RHA, fa/ta and Sp dosages on the Responses}

\subsubsection{Slump value (Y1)}

Figure 4 .a shows the perturbation of a slump when w/b of 0.25 , binder $550 \mathrm{~kg} / \mathrm{m}^{3}, 10 \%$ RHA, ratio fa/ta of 0.4 and Sp dosage of $0.9 \%$. Through this graph, it can be seen how the changing quantity of input variables affects to slump value of fresh concrete while others maintain to be constants. Increasing w/b (A) or Sp dosage (E) affect the increase of slump. However, increasing percentages replacement cement with RHA (C) or binder content (B) reduces the slump. Increasing ratio fa/ta (D) in the varying of 0.35 up to 0.45 is not significantly change the slump of HSHPC. When the high percentage of Sp dosage applied is $1.3 \%$, the slump value is almost double compared to that of dosage of $0.5 \%$. Figure $4 . b$ presents 3D response surface and contour plots to interpret the interaction two selection variables to the slump. Changing to those variables is significantly changing the slump value. It also shows that the effect of SP has a limitation as beyond that optimum dosage there is no significant effect on slump value which called as saturated point. 

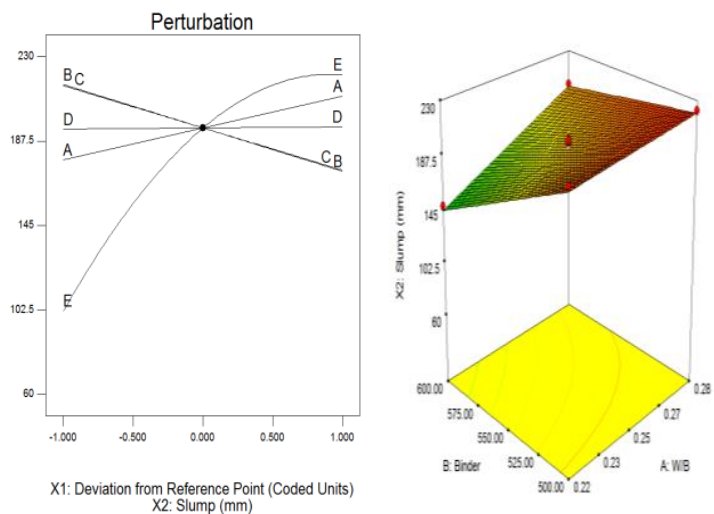

Fig. 4 (a) The perturbation of a slump when w/b of 0.25 , binder $550 \mathrm{~kg} / \mathrm{m} 3,10 \%$ RHA, ratio fa/ta of 0.4 and Sp dosage of $0.9 \%$ (b) Response surface plots vs Slump value for function of $w / b$ and Binder

\subsubsection{1-day Compressive strength (Y2)}

Figure 5.a shows the perturbation of 1-day compressive strength when $w / b$ of 0.25 , binder $550 \mathrm{~kg} / \mathrm{m} 3,10 \% \mathrm{RHA}$, fa/ta of 0.4 and Sp dosage of $0.9 \%$. Increasing w/b (A) or binder (B), RHA content (C) and Sp dosage (E) affect the increase of compressive strength at age of 1 day. However, increasing the RHA content reduces the compressive strength and increasing ratio fa/ta (D) in the range of 0.35 up to 0.45 is not significantly changing 1-day compressive strength. At the high Sp dosage of 1.3\%, the compressive strength at age of 1 day is higher $40 \%$ than that of dosage of $0.5 \%$. Figure $5 \mathrm{~b}$ presents $3-\mathrm{D}$ response surface and contour plots to interpret the interaction two selection variables to the 1-day compressive strength. The optimum of 1-day compressive strength seems on w/b 0.25 and $10 \%$ RHA while the other keeping in constant.
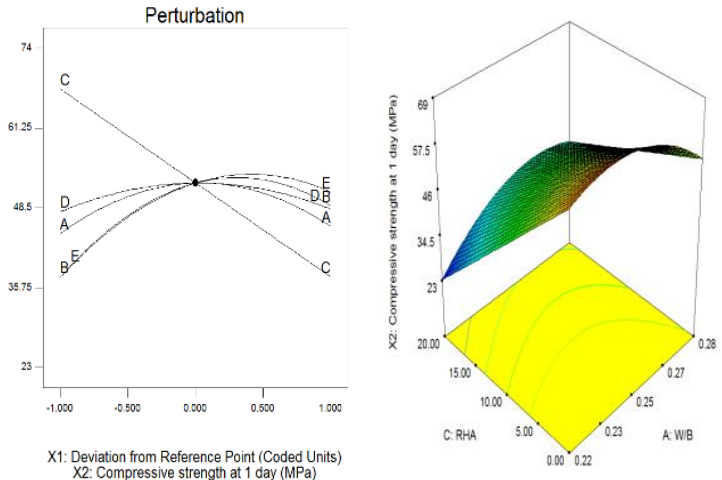

Fig. 5 (a) The perturbation of compressive strength at 1day when w/b of 0.25 , binder of 550 $\mathrm{kg} / \mathrm{m}^{3}, 10 \%$ of RHA, ratio fa/ta of 0.4 and Sp dosage of $0.9 \%$. (b) Response surface plots vs 1 days compressive strength for function of W/b and RHA

\subsubsection{8-day Compressive strength (Y3)}

Figure 6.a shows the perturbation of 28 -day compressive strength when w/b of 0.25 , binder of $550 \mathrm{~kg} / \mathrm{m}^{3}, 10 \%$ of RHA, ratio fa/ta of 0.4 and Sp dosage of $0.9 \%$. Changing W/b 
(A), binder content (B) or Sp dosage (E) significantly affects the on compressive strength at age of 28 days. However, the increasing RHA content more than $10 \%$ reduces the 28 -day compressive strength. Changing the ratio of fa/ta in the varying of 0.35-0.45 is not significantly change the 28 -day compressive strength while at the Sp dosage of $1.3 \%$, the compressive strength at age of 28 -days is higher than that of dosage of $0.5 \%$. There was no sign of segregation and bleeding of fresh RHA concrete at a Sp dosage of $1.3 \%$. According to Chang the proper percentages dosage of Sp improves the flowability of concrete at low w/b ratios due to the friction between packed granular materials are reduced. Then, the strengths of RHA concrete are improved due to the RHA concrete is denser which related to hydration produced $\mathrm{CaOH}$ and then reacted with $\mathrm{SiO}_{2}$ from RHA created more $\mathrm{CSH}$. Figure $6 \mathrm{~b}$ present 3-D response surfaces and contour plots to interpret the interaction two selection variables to the compressive strength at age of 28 days. The strength seems optimum on w/b 0.25 and $10 \%$ RHA while the other keeping in constant. There is increased in compressive strength as well if the binder content increased while other keeping in constant. The compressive strength seems to reach the ceiling while increasing binder and reducing $\mathrm{w} / \mathrm{b}$ of mix proportion the strength reach almost similar strength that of w/b of 0.25 , binder $550 \mathrm{~kg}$ and $10 \%$ RHA. It could be the strength of coarse aggregate already reaches its ultimate. At a certain level, the concrete strength was determined by the aggregate strength as the matrix and the interface transition zone was improved through applying lower w/b and incorporating RHA [20]. The results of the present models are higher than previous models proposed by Islam et al. [9] and it could be the different mixing method applied affected to different results on the slump value and the compressive strength. The two step mixing procedures produce more homogenous mixes than conventional mixing procedures [21].
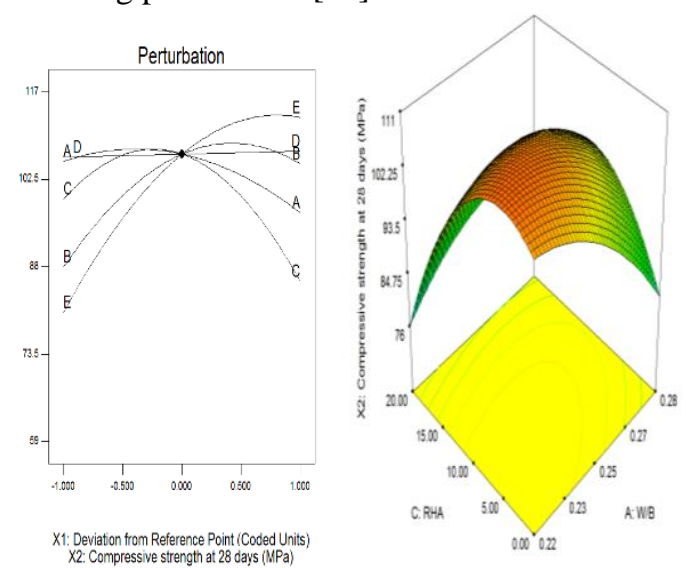

Fig. 6 (a) The perturbation of compressive strength at age of 28 days while w/b of 0.25 , binder of $550 \mathrm{~kg} / \mathrm{m} 3,10 \%$ of RHA, ratio fa/ta of 0.4 and Sp dosage of $0.9 \%$. (b). Response surface plots vs the compressive strength for function of W/b and RHA

\subsection{Optimization Using the Desirability Functions}

In order to find the high compressive strength of HSHPC incorporating RHA, the significant input parameters have to be optimized. The optimization process of mix proportion of HSHPC was accomplished by using numerical optimization. The desirability function approach was then used to govern the optimum proportions of $w / b$, binder content, percentages of RHA, ratio fa/ta and percentages dosage of $\mathrm{Sp}$ to produce HSHPC by 
simultaneously maximizing the slump value, 1 and 28-day compressive strength. To produce HSHPC at low cost, the binder content and percentages dosage of Sp are the lowest possible, meanwhile the partial replacement RHA is in the maximum requirement. In addition, the level of the ratio fa/ta was within the varying of $0.35-45$. The responses on slump value, compressive strength at agev of 1 and 28-days were set for maximum desirability. The best mix proportion was located in Figures 7 at w/b of 0.26 , binder content of $552.82 \mathrm{~kg} / \mathrm{m} 3$, partial replacement cement with RHA of $10.48 \%$, ratio fa/ta of 0.4 , Sp dosage of $0.93 \%$ and desirability of 0.609 . These optimum values were checked experimentally which resulted in slump value compressive strength at age of 1 and 28 days were $207 \mathrm{~mm}, 52.7 \mathrm{MPa}$ and 110 $\mathrm{MPa}$, respectively. The experimental results of slump, 1 and 28-day compressive strength were $210 \mathrm{~mm}, 51 \mathrm{MPa}$ and $108 \mathrm{MPa}$. The variations between the predicted and experimental are $1.4 \%, 3.3 \%$ and $1.9 \%$, respectively. The good correlation was found between these two results obtained from the optimization analysis using desirability functions and the experiment. It can be concluded that Box-Behnken design including desirability functions could be effectively applied to optimize the mixes.

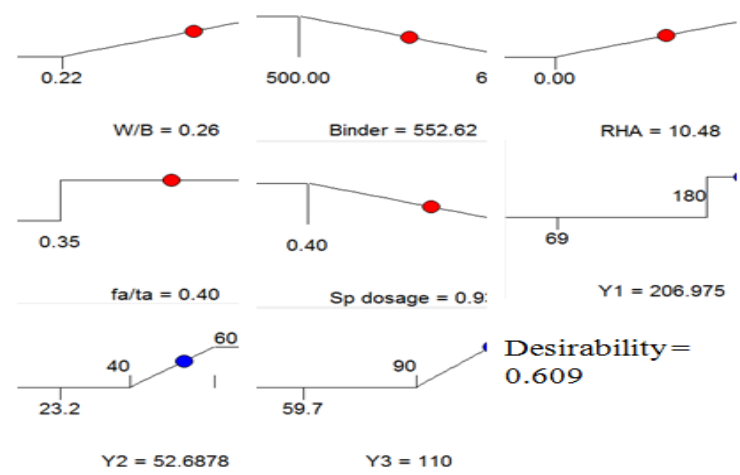

Fig. 7 Desirability ramps for numerical optimization of four selected goals

\section{Conclusions}

The models presented facilitate the prediction of the slump value, compressive strength of HSHPC at age of 1 and 28-day based on the input of mix proportion.

1. Response surface methodology by the Box-Behnken model was used to examine five ingredients of HSHPC to predict and optimize the responses of slump, 1 and 28-day compressive strength.

2. A quadratic regression model could properly predict the experimental data with the $\mathrm{R}^{2}$ value of $0.9945,0.9748$ and 0.9856 for slump, 1 and 28-day compressive strength, respectively.

3. The simultaneous optimization of the multi-response system by desirability function indicated that the compressive strength of $100 \mathrm{MPa}$ at age of 28 days can be produced by w/b of 0.26 , binder content of $552.82 \mathrm{~kg} / \mathrm{m}^{3}$, partial replacement cement with RHA of $10.48 \%$, ratio fa/ta of 0.4 , percentages dosage of Sp dosage of $0.93 \%$.

4. In the future, it is recommended that the different maximum aggregate size of coarse aggregates should be included in studying parameters. It is believed that changing the 
maximum size of aggregates influences the value of slump and the compressive strength of concrete as well.

\section{Acknowledgements}

The authors would like to thank the Ministry of Science and Environment Malaysia for awarding the UMRG grant No: UMRG RP018/2012C to carry out the research on high strength rice husk ash concrete. The help of BASF (M) Sdn. Bhd. in supplying the superplasticizer is highly appreciated.

\section{References}

[1] G. A. Habeeb and M. M. Fayyadh, "Rice Husk Ash Concrete: The effect of RHA average particle size on mechanical properties and drying shrinkage," Aust. J. Basic Appl. Sci., vol. 3, no. 3, pp. 1616-1622, 2009.

[2] P. Chindaprasirt, C. Jaturapitakkul, and U. Rattanasak, "Influence of fineness of rice husk ash and additives on the properties of lightweight aggregate," Fuel, vol. 88, no. 1, pp. 158-162, 2009.

[3] G. C. Cordeiro, R. D. Toledo Filho, and E. De Moraes Rego Fairbairn, "Use of ultrafine rice husk ash with high-carbon content as pozzolan in high performance concrete," Mater. Struct. Constr., vol. 42, no. 7, pp. 983-992, 2009.

[4] H. Bin Mahmud, M. F. A. Malik, R. A. Kahar, M. F. M. Zain, and S. N. Raman, "Mechanical Properties and Durability of Normal and Water Reduced High Strength Grade 60 Concrete Containing Rice Husk Ash,” J. Adv. Concr. Technol., vol. 7, no. 1, pp. 21-30, 2009.

[5] R. Madandoust, M. M. Ranjbar, H. A. Moghadam, and S. Y. Mousavi, "Mechanical properties and durability assessment of rice husk ash concrete," Biosyst. Eng., vol. 110, no. 2, pp. 144-152, 2011.

[6] J. H. S. Rêgo, A. A. Nepomuceno, E. P. Figueiredo, and N. P. Hasparyk, "Microstructure of cement pastes with residual rice husk ash of low amorphous silica content," Constr. Build. Mater., vol. 80, pp. 56-68, 2015.

[7] S. BAHRI and H. B. MAHMUD, "Rice Husk Ash-An Alternative Material to Silica Fume For Production Of 100 MPa Mortar,” Electron. J. Struct. Eng., vol. 13, p. 1, 2013.

[8] P. Mehta Kumar and P. J. M. Monteiro, Concrete: microstructure, properties, and materials. McGraw-Hill Publishing, 2006.

[9] M. N. Islam, M. F. Mohd Zain, and M. Jamil, "Prediction of Strength and Slump of Rice Husk Ash Incorporated High-Performance Concrete," J. Civ. Eng. Manag., vol. 18, no. 3, pp. 310-317, 2012.

[10] N. Van Tuan, G. Ye, K. Van Breugel, and O. Copuroglu, "Hydration and microstructure of ultra high performance concrete incorporating rice husk ash," Cem. Concr. Res., vol. 41, no. 11, pp. 1104-1111, 2011.

[11] L. A. Bui, C. Chen, C. Hwang, and W. Wu, "Effect of silica forms in rice husk ash on the properties of concrete," Int. J. Miner. Metall. Mater., vol. 19, no. 3, pp. 252-258, 
Mar. 2012.

[12] K. Ganesan, K. Rajagopal, and K. Thangavel, "Rice husk ash blended cement: Assessment of optimal level of replacement for strength and permeability properties of concrete," Constr. Build. Mater., vol. 22, no. 8, pp. 1675-1683, 2008.

[13] S. Bhanja and B. Sengupta, "Investigations on the compressive strength of silica fume concrete using statistical methods," Cem. Concr. Res., vol. 32, no. 9, pp. 1391-1394, 2002.

[14] A. Ghezal and K. H. Khayat, "Optimizing self-consolidating concrete with limestone filler by using statistical factorial design methods," ACI Mater. J., vol. 99, no. 3, pp. 264-272, 2002.

[15] Q. Li, L. Cai, Y. Fu, H. Wang, and Y. Zou, "Fracture properties and response surface methodology model of alkali-slag concrete under freeze-thaw cycles," Constr. Build. Mater., vol. 93, pp. 620-626, 2015.

[16] A. N. Givi, S. A. Rashid, F. N. A. Aziz, and M. A. M. Salleh, "Assessment of the effects of rice husk ash particle size on strength, water permeability and workability of binary blended concrete," Constr. Build. Mater., vol. 24, no. 11, pp. 2145-2150, 2010.

[17] P. Goltermann, V. Johansen, and L. Palbøl, "Packing of aggregates: An alternative tool to determine the optimal aggregate mix," ACI Mater. J., vol. 94, no. 5, pp. 435443, 1997.

[18] P. L. J. Domone and M. N. Soutsos, "Approach to the proportioning of high-strength concrete mixes," Concr. Int., vol. 16, no. 10, pp. 26-31, 1994.

[19] H. T. Le, S. T. Nguyen, and H.-M. Ludwig, "A Study on High Performance FineGrained Concrete Containing Rice Husk Ash," Concr. Struct. Mater., vol. 8, no. 4, pp. 301-307, 2014.

[20] A. Cetin and R. L. Carrasquillo, "High-performance concrete: influence of coarse aggregates on mechanical properties," Mater. J., vol. 95, no. 3, pp. 252-261, 1998.

[21] T. D. Rupnow, V. R. Schaefer, K. Wang, and B. L. Hermanson, "Improving portland cement concrete mix consistency and production rate through two-stage mixing," 2007. 